\title{
Cone-beam Computed Tomography: A Resolution to Paradoxical Judgments in Endodontic Diagnosis
}

\author{
${ }^{1}$ Amruta R Chougule, ${ }^{2} \mathrm{M}$ Kundabala, ${ }^{3}$ Rayapudi P Mohan, ${ }^{4}$ Neeta Shetty
}

\begin{abstract}
Recently, various diagnostic tools have emerged with a view to enhance endodontic treatment. Cone-beam computed tomography $(\mathrm{CBCT})$ is presented as a new endodontic tool. The narrow field CBCT reduces the negative effects of anatomic noise, geometric distortion, and technique sensitivity observed on two-dimensional images. It can be used to identify canal morphology, numbers of canals, and relative positioning even in the presence of calcific metamorphosis (CM) and dystrophic calcifications. Calcific metamorphosis is characterized by the deposition of hard tissue within the pulp canal space. Most of the literature advices the treatment of $\mathrm{CM}$ through observation and periodic examination. Thus, it is imperative for the clinician to identify calcified canals preoperatively for conservative treatment approach. This case series illustrates about the versatility of $\mathrm{CBCT}$ over the conventional radiology for detecting calcified canals.
\end{abstract}

Keywords: Calcific metamorphosis, Cone-beam computed tomography, Endodontic diagnostic

How to cite this article: Chougule AR, Kundabala M, Mohan RP, Shetty N. Cone-beam Computed Tomography: A Resolution to Paradoxical Judgments in Endodontic Diagnosis. World J Dent 2016;7(2):100-106.

\section{Source of support: Nil}

Conflict of interest: None

\section{INTRODUCTION}

The two essential components of endodontic diagnosis are clinical examination and diagnostic imaging. Accurate diagnostic imaging supports the clinical diagnosis and allows the better visualization of the area of interest. Assessment of areas of interest in three dimensions might benefit even the experienced clinician. The most commonly used diagnostic aids in endodontics are conventional radiography and digital radiography, and recently included cone-beam computed tomography (CBCT). Digital radiography offers the benefit of less radiation exposure, faster image acquisition, no requirement for

\footnotetext{
${ }^{1,3}$ Postgraduate Student, ${ }^{2}$ Professor, ${ }^{4}$ Professor and Head

${ }^{1-4}$ Department of Conservative Dentistry and Endodontics Manipal College of Dental Sciences, Mangaluru, Karnataka, India
}

Corresponding Author: M Kundabala, Professor, Department of Conservative Dentistry and Endodontics, Manipal College of Dental Sciences, Light House, Hill Road, Mangaluru, Karnataka India, Phone: +919845837187, e-mail: kundakamath@gmail.com chemicals, and a number of image processing tools. Conventional radiography has numerous disadvantages, inability to manipulate images, higher required dosages, inability to archive images, and increased time between exposure and image interpretation. These problems associated with conventional radiography may be overcome using small volume CBCT imaging techniques which can produce three-dimensional (3D) images of individual teeth and the surrounding tissues. ${ }^{1}$ Studies have shown that $\mathrm{CBCT}$ is an important tool for diagnosing root canal system anatomy. ${ }^{2,3}$

Pulp canal obliteration (PCO), also called calcific metamorphosis (CM), is characterized by the deposition of hard tissue within the root canal space and a yellow discoloration of the clinical crown. ${ }^{4}$ Hillmann and Geurtsen ${ }^{5}$ reported that percentage of calcified canals was around 3\% for age group of 10 to 30 years and 13\% for 31 to 72 years. Thus, it is important to confirm the presence or absence of calcification before starting endodontic treatment. The clinician has natural tendency to cut more dentin in search of root canals. But use of CBCT preoperatively to assess the root canal morphology not only helps to limit access cavity preparation but also conserves tooth structure and saves valuable time. There is very few literature on the use of CBCT in detection of calcified canals. This case series demonstrates usefulness of preoperative $\mathrm{CBCT}$ for diagnosis and confirmation of calcified root canals.

\section{CASE REPORTS}

\section{Case 1}

A 28-year-old male patient with noncontributory medical history reported to the Postgraduate Department of Endodontics with a chief complaint of pain in upper right back tooth. Clinical examination revealed deep class II secondary caries in maxillary right second permanent molar (Fédération Dentaire Internationale, FDI 17), which was tender to percussion. The preoperative diagnostic radiograph revealed occlusal radiolucency, approaching the pulp space with periodontal ligament space widening and loss of lamina dura and incompletely obturated root canals. From the clinical and radiographic findings, a diagnosis of symptomatic irreversible pulpits with symptomatic apical periodontitis was made for tooth 17, and reroot canal treatment was scheduled. 
After administering local anesthesia (posterior superior nerve block) with 2\% lignocaine containing 1:2,00,000 adrenaline (Lox 2\%, Neon Laboratories Limited, Andheri (East), Mumbai, India), tooth was isolated with rubber dam. The tooth surface, rubber dam, and clamp were disinfected using Moller's technique. Access cavity was prepared under water coolants using high-speed hand piece (NSK Pana Air, Japan) and Endo Access No. 3, Endo Zee bur (Dentsply Maillefer, Switzerland), and three canal orifices were identified (MB, DB Palatal). Gutta-percha was removed from distobuccal canal. Palatal and mesiobuccal (MB) canals were not obturated. Distobuccal and palatal canals were instrumented with K-file number 15 (Dentsply Maillefer, Switzerland), but $\mathrm{MB}$ canal was not negotiated. So we decided to perform multisliced scans of the maxilla with informed consent from the patient. The second molar was focused, and the morphology was obtained in transverse, axial, and sagittal sections of $0.075 \mathrm{~mm}$ thickness using Endomode of the small field of view (FOV) CBCT scan (Planmeca Pro-Max 3d Mid, Romexies 3.25 software). Axial view revealed that mesial root has one canal which was patent only in coronal third, while it was calcified from middle to apical third of root (Figs 1A to D).

\section{Case 2}

A 55-year-old female patient reported to the Postgraduate Department of Endodontics with a chief complaint of pain in the lower right back tooth. Clinical examination revealed the presence of metal crown with respect to tooth 46 (FDI), and the tooth was tender on percussion. Preoperative intraoral periapical (IOPA) radiograph revealed periapical radiolucency with respect to mesial and distal root. The metal crown was removed using Morrell Crown Remover Set (Miltex, Plainsboro, NJ, USA). Pulp sensibility testing of the tooth 46 with heated gutta-percha (Dentsply Maillefer, Ballaigues, Switzerland) and ice cube caused an intense lingering pain. Based on clinical and radiographic examination, diagnosis of symptomatic irreversible pulpitis with symptomatic apical periodontitis was made.

After administering local anesthesia, same procedure was followed for disinfection and access cavity preparation.
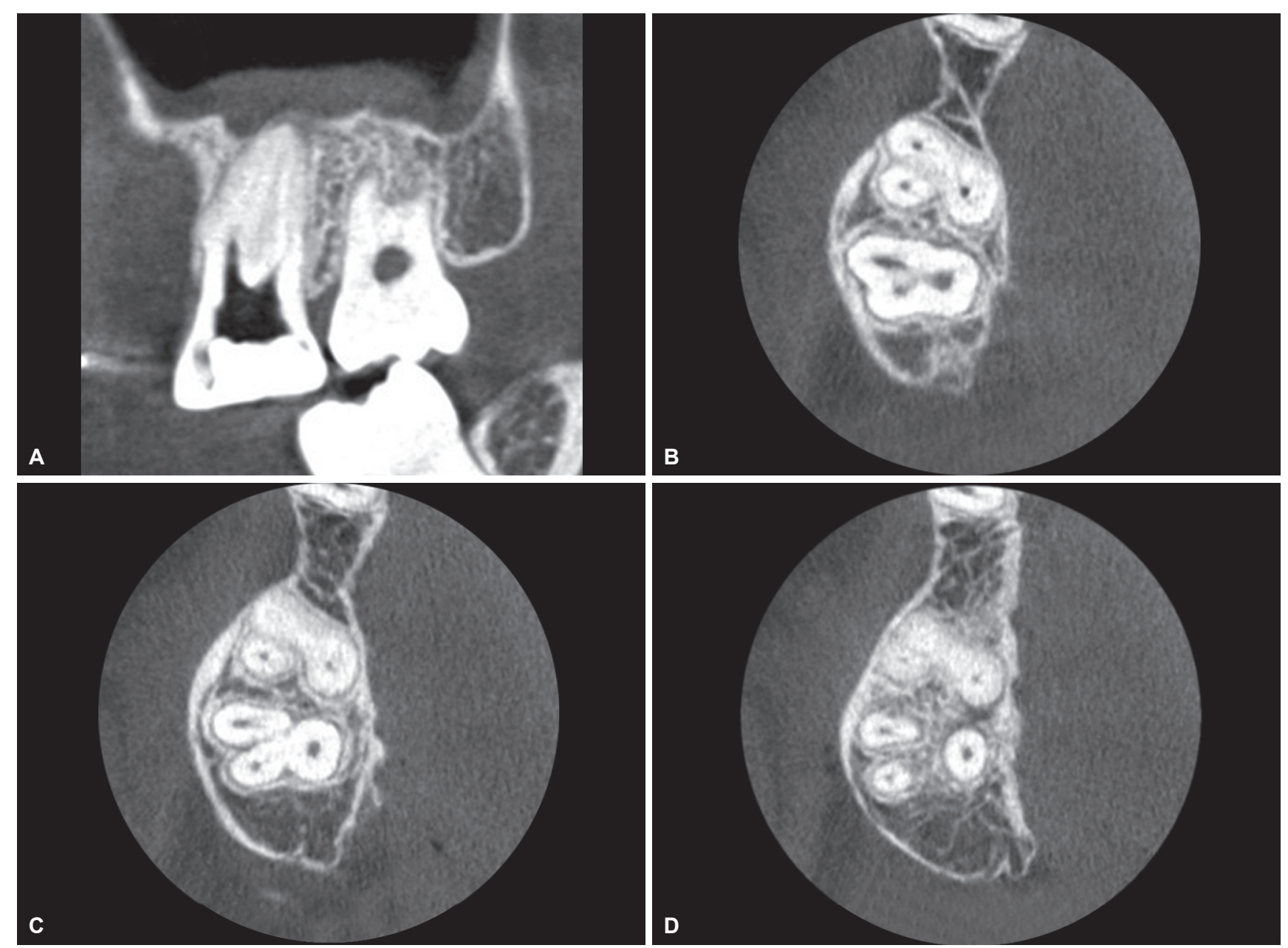

Figs 1A to D: (A) Sagittal view revealed the patency of MB canal in coronal third, calcified from middle third from apical third, (B) axial view revealed the patency of MB canal in coronal third, (C) axial view revealed calcified MB canal in middle third, and (D) axial view revealed calcified MB canal in apical third. MB: mesiobuccal (Case 1) 


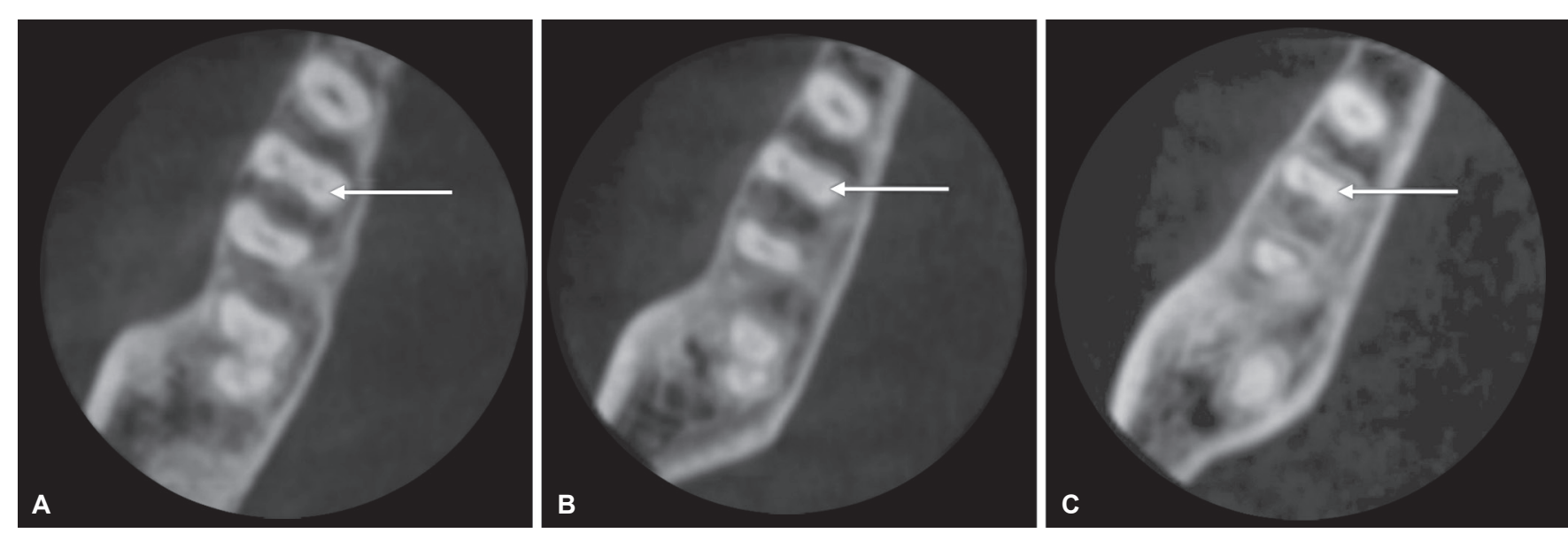

Figs 2A to C: Axial view: (A) Coronal third of root canal, patent $M B, M L$, and $D B$ canal, $(B)$ middle third of root canal, patent $M B$ and $D B$ canal while calcified ML canal, and $(C)$ apical third of root canal, patent MB and DB canal while calcified ML canal. MB: Mesiobuccal; $\mathrm{ML}$ : Mesiolingual; DB: Distobuccal (Case 2)

Access cavity was prepared, and three canal orifices were identified. Distal canal was instrumented with K-file number 15 (Dentsply Maillefer, Switzerland), but mesiolingual and MB canals were not negotiated. So we decided to perform multisliced scans of the mandible with informed consent from the patient. The first molar was focused, and the morphology was obtained in transverse, axial, and sagittal sections of $0.075 \mathrm{~mm}$ thickness using Endomode of the small FOV CBCT scan. Axial view revealed that mesial root has two canals of that $\mathrm{MB}$ canal was patent from orifice to apex; however, mesiolingual canal is patent only in coronal third, while it was calcified from middle to apical third of root (Figs 2A to C).

\section{Case 3}

A 59-year-old female patient reported to the Postgraduate Department of Endodontics with a chief complaint of food lodgment in the lower left back tooth. Clinical examination revealed dislodged restoration with respect to tooth 36 (FDI). Pulp sensibility testing of the tooth with heated gutta-percha (Dentsply Maillefer, Ballaigues, Switzerland), ice cube, and electric pulp stimulation (Parkel Electronics Division, Farmingdale, NY, USA) caused no response. Radiographic examination revealed widening of lamina dura with respect to mesial and distal root. Based on clinical and radiographic examination, diagnosis of pulp necrosis with asymptomatic apical periodontitis was made. The same procedure was followed for access opening and confirmation of calcified canal as per case two (Figs 3A to D).

\section{Case 4}

A 26-year-old male reported to the Postgraduate Department of Endodontics with a chief complaint of pain in the upper front tooth region. Patient gave history of trauma 5 years back and also history of root canal treat- ment started with respect to teeth 11 and 21 in a private clinic. She also informed that the previous dentist was not able to negotiate root canal of one of the teeth, so he had suggested her to undergo periradicular surgery, as negotiation of the calcified canal was impossible and not worth the risk. The patient then visited our department for enquiring an alternative treatment option to surgical procedure. On clinical examination with respect to teeth 11 and 21, there was the presence of temporary filling. Pulp sensibility test was done to confirm that both 11 and 21 were not responding to any test. Intraoral periapical radiograph revealed periapical radiolucency associated with 11 which was approximating toward mesial aspect of 21 in apical region and also revealed the presence of $\mathrm{CM}$ with respect to 21 .

Patient was then advised for a small FOV CBCT for the upper maxillary region to have a better understanding of the root canal and periradicular region. The examination of the different slices of the CBCT images in various planes (sagittal and coronal planes) revealed the presence of patent canal with respect to 21 (Figs $4 \mathrm{~A}$ and B).

\section{Case 5}

A 54-year-old female with noncontributory medical history reported to the Postgraduate Department of Endodontics with a chief complaint of discoloration of teeth in the lower right back region. On clinical examination, teeth 44 and 45 were discolored. Pulp sensibility test demonstrated that both 44 and 45 were not responding. A diagnosis of pulp necrosis was made. Intraoral periapical radiograph revealed patent canals in coronal and middle third region but middle third to apical third region with respect to 45 was not patent. The calcification was confirmed with the use of CBCT in apical third region (Figs 5A and B). Root canal treatment was completed till that level. 

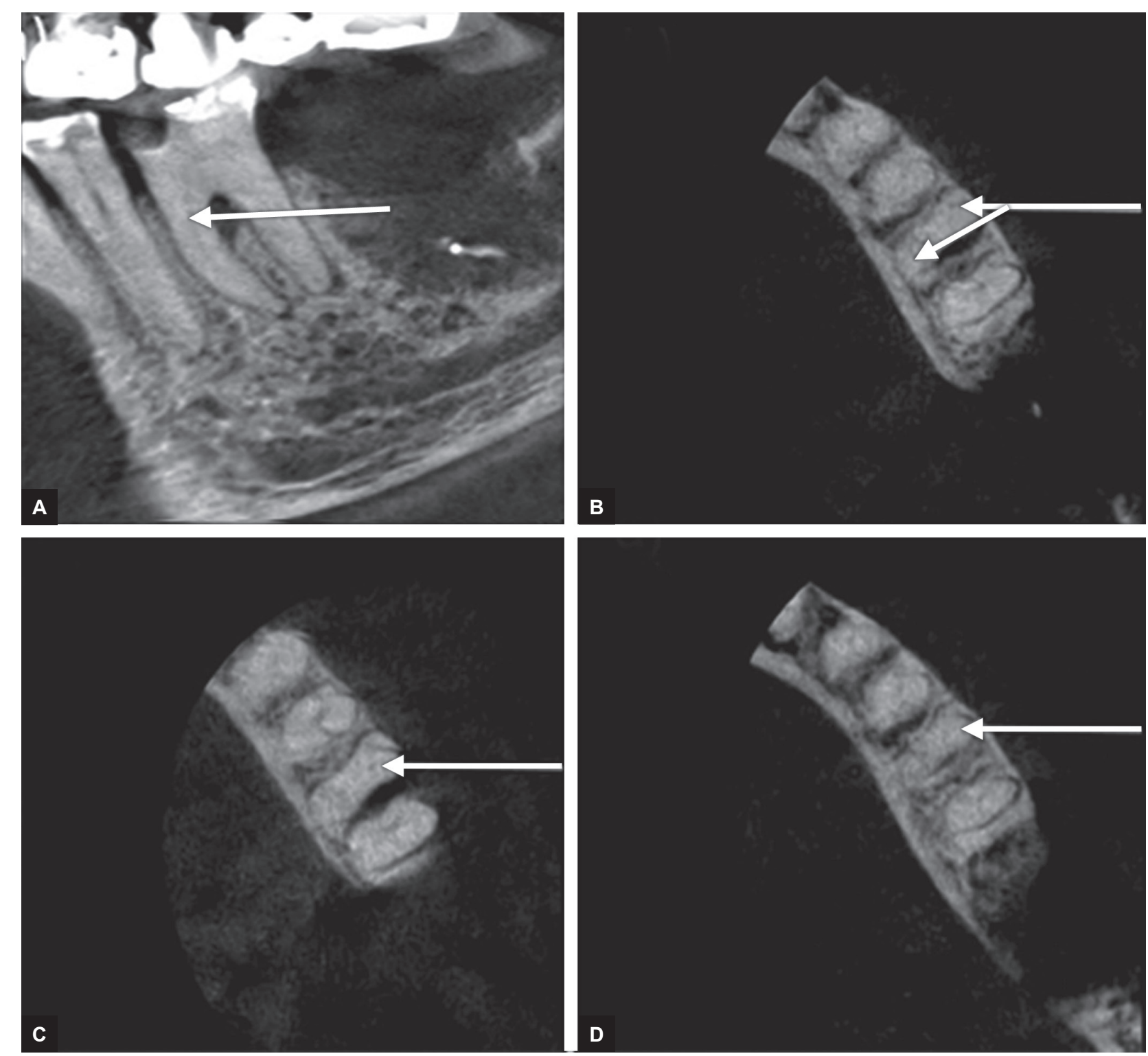

Figs 3A to D: (A) Sagittal view revealed the patency of MB canal, (B) axial view revealed the patency of MB and ML canal in coronal third, (C) axial view revealed calcified ML canal in middle third, and (D) axial view revealed calcified ML canal in apical third. MB: Mesiobuccal; ML: Mesiolingual (Case 3)
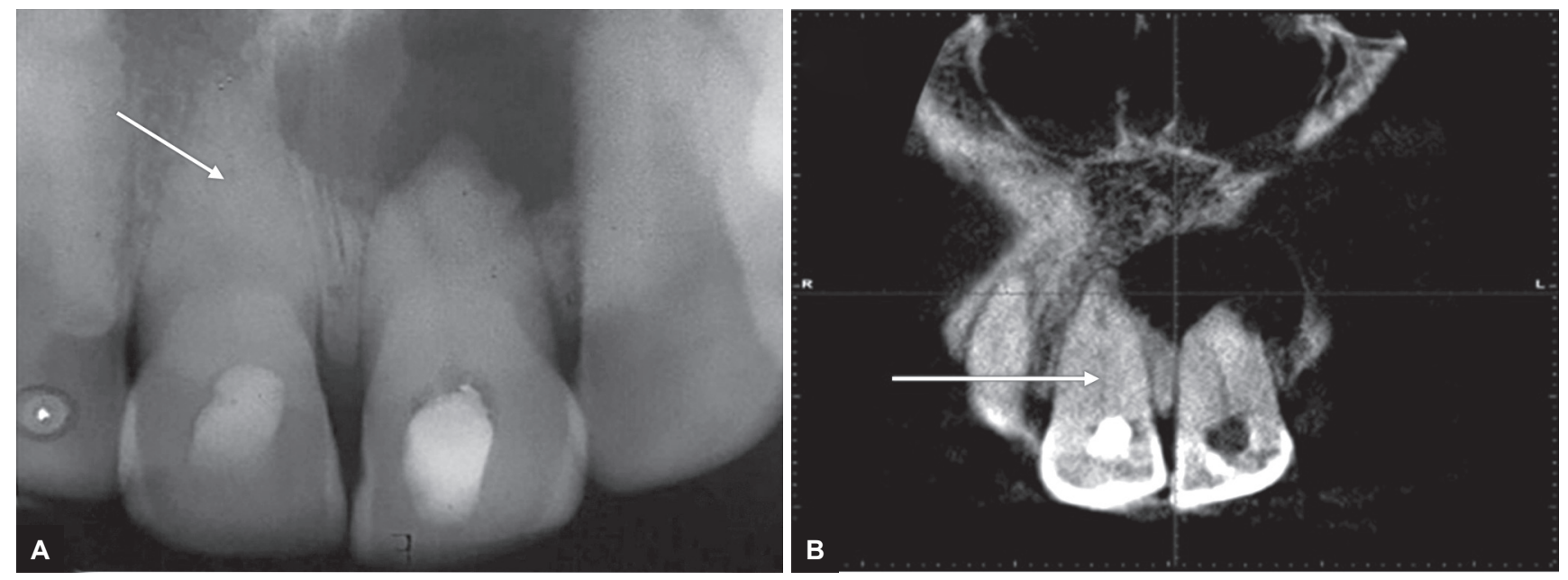

Figs 4A and B: (A) Intraoral periapical radiograph showing calcification of 21 , and (B) cone-beam computed tomography coronal view revealed patent canal with respect to 21 (Case 4) 

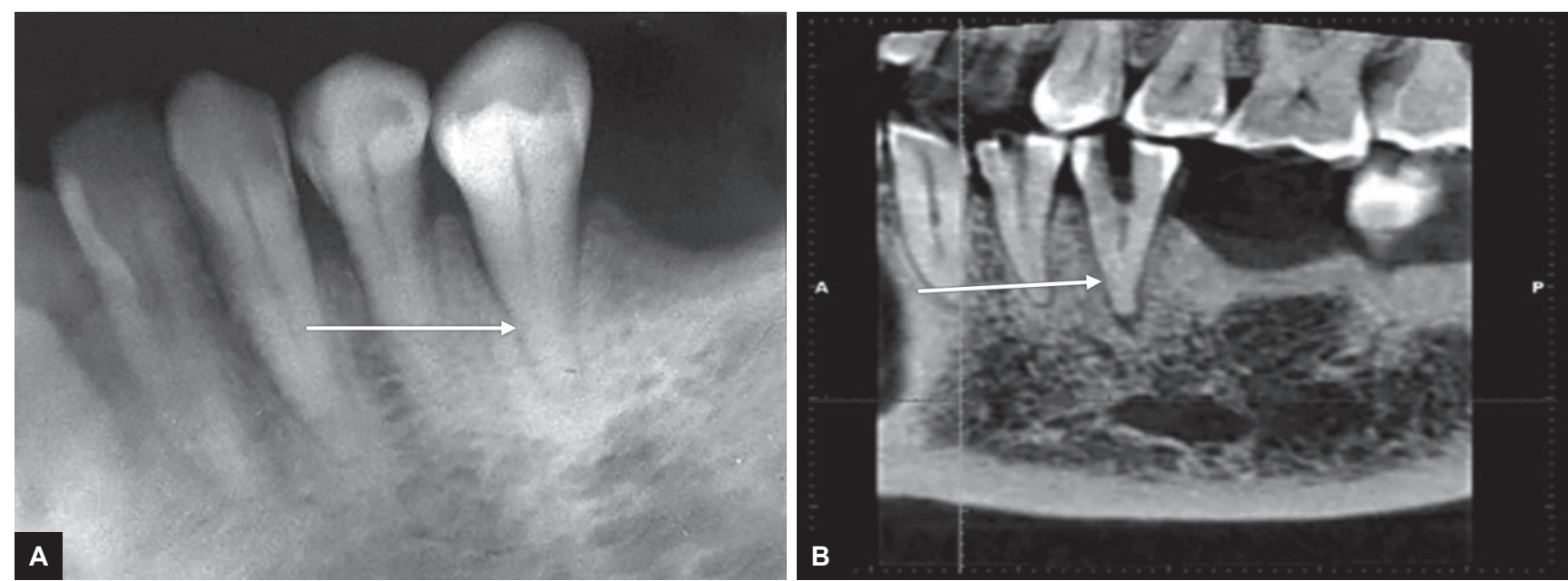

Figs 5 A and B: $(A)$ Intraoral periapical radiograph, and $(B)$ cone-beam computed tomography in sagittal view confirmed calcification in middle third of lower premolars (Case 5)
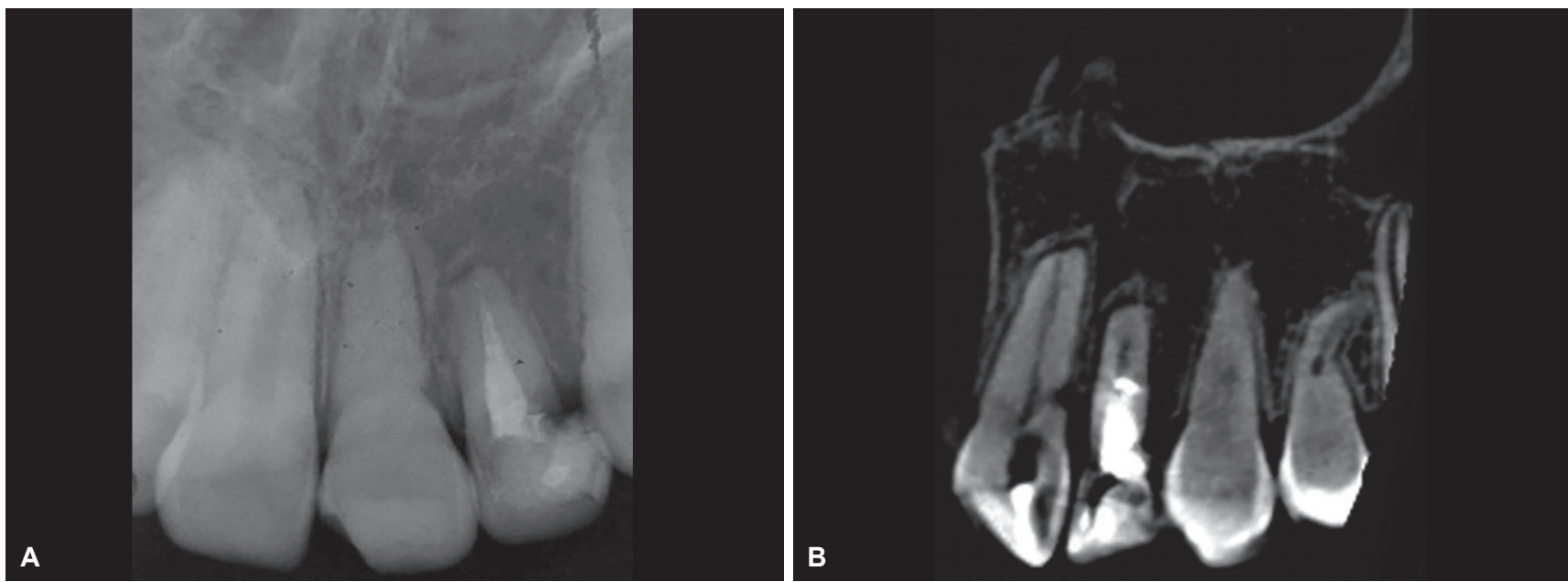

Figs 6 A and B: (A) Intraoral periapical radiograph showing calcification of 21 , and (B) cone-beam computed tomography coronal view revealed patent canal and external root resorption with respect to 21 (Case 6)

\section{Case 6}

A 14-year-old male patient was referred from the Department of Orthodontics for evaluation of vitality testing with respect to 21. Pulp sensibility testing with respect to tooth was negative. Intraoral periapical radiograph revealed CM and the presence of external root resorption. We started access cavity under rubber dam but could not locate the canal. So small FOV CBCT was advised to check for the patency of the canal. Cone-beam computed tomography findings revealed the presence of canal and external root resorption (Figs 6A and B). Then, the canal was located under surgical microscope.

\section{DISCUSSION}

Radiographic imaging plays a vital role in clinical assessment of endodontic patient. In 1899, Kells was the first to report the use of "radiogram" to determine length of root canal by using lead wire. ${ }^{6,7}$ Later computed tomography (CT) and micro-CT scan were used for maxillofacial imaging. But its use in dentistry is limited due to many demerits such as increased dose of radiation, high cost, and access. In 1996, introduction of CBCT in dentistry demonstrated application of 3D imaging for endodontic considerations. ${ }^{8}$ Narrow FOV, that is, small FOV $40 \times 50$ $\mathrm{mm} \mathrm{CBCT}$, used in our cases facilitates diagnosis, treatment, and outcome assessment while adhering to As Low As Reasonably Achievable (ALARA) principles. ${ }^{9,10}$ It has the unique ability to provide high-resolution images in multiple planes. ${ }^{11}$ Cone-beam computed tomography provides the clinician with the ability to observe an area of interest in three different planes (transverse, sagittal, and axial) and thus acquire 3D information and eliminate superimposition of surrounding structures. ${ }^{11}$ Regions of interest can be compared over time without the need to replicate the radiation geometry. A review by Taylor et al reported on the many possible endodontic applications of CBCT which include diagnosis of endodontic pathology and canal morphology, assessment of pathosis of nonendodontic origin, evaluation of root fractures and 
trauma, analysis of external and internal root resorption and invasive cervical resorption, and presurgical planning. ${ }^{12}$ Simon et $\mathrm{l}^{13}$ reported that the CBCT might provide more accurate diagnostic information than biopsy and histology when evaluating large periapical lesions. We have used endodontic imagining mode of CBCT which allows each root and its surrounding structures to be evaluated and accurately measured with extreme high resolution and voxel size of $75 \mu \mathrm{m}$. This mode provides the finest anatomical details. Thus, it is used in these cases for confirmation of calcified canals. Moreover, any failure in identifying canal will lead to reinfection and failure of root canal therapy. Depending only on periapical radiography sometimes may lead to missed canals or mistaking patent canal for calcified ones.

Calcific metamorphosis is defined as a pulpal response to trauma or any chronic irritation, i.e., characterized by deposition of hard tissue within the root canal space. This type of response is also seen in aging process. This uncontrolled mineralization results due to various irritants such as failure of enzyme, pyrophosphatase, reduction in capillary permeability, and reduction in blood supply. To locate the calcified orifice, the practitioner first mentally visualizes and projects the normal spatial relationship of the pulp space onto a radiograph of the calcified tooth. Then, the two-dimensional radiographic image is correlated with the 3D morphology of the tooth. ${ }^{14}$ Thereafter, access preparation is initiated, and this approach requires knowledge of the normal pulp chamber location, root canal anatomy, and the long axis of the roots. Accurate radiographs are essential for preoperative visualization and periodic assessment of bur penetration and orientation. ${ }^{15}$ But if root canal in teeth in which calcific deposits have blocked access to the canal(s), treatment efforts are often thwarted. An effort to locate the residual canal may remove large amounts of dentin, and there is a risk of perforating or fracturing the root. ${ }^{16}$ Thus, it is very necessary to confirm the patency of canal before initiating access.

In case one, $\mathrm{MB}$ canal was tried to locate with the access bur but could not be located since the canal of tooth 17 was calcified. To prevent iatrogenic perforation, we advised CBCT to confirm the patency of the canal, which has shown obliteration of pulp canal space. Due to young age of the patient, the calcification found in the canal can be attributed to long-standing irritation from the carious lesion which has resulted in PCO. ${ }^{17}$ In case two, chronic irritation response to operative procedure resulted in PCO. In case three, tooth 36 was having large resin composite restoration which was fractured. Intraoral periapical radiograph revealed calcified canals. After access opening, only distal canal was found. So to locate mesial canals, CBCT was taken. Scanning revealed thin and patent MB canal, while mesiolingual canal was obliterated. This may be attributed to long-term irritational response to resin composite restoration. ${ }^{17}$

In case four, the calcification response might be attributed to pulpal irritation due to trauma. ${ }^{18}$ Long-standing pulpal response to chronic irritation was found in case five. ${ }^{19}$ In case six, the orthodontic tooth movement might have been the reason for the pulp space obliteration. According to previous studies, trauma, exogenous irritation such as caries, leaking restorations, fracture lines, orthodontic movements are considered to have the greatest impact on the apical region and pulpal blood supply. ${ }^{20}$ As shown in our cases, conventional IOPA radiograph revealed the absence of canal, but $\mathrm{CBCT}$ scans confirmed the presence of canal. Wherever the CBCT confirmed the calcification, exploration for canal location was stopped to prevent unnecessary destruction of dentin. Thus, CBCT is an excellent tool to confirm the patency of the canal.

Lundberg and $\mathrm{Cvek}^{21}$ have concluded that tissue changes in the pulps of teeth with CM do not indicate the necessity for root canal treatment. Most of the literature does not support endodontic intervention unless periradicular pathosis is detected or the involved tooth becomes symptomatic. Because the overall failure rate of nonsurgical root canal treatment is between 10 and 19\%, it may be advisable to manage cases demonstrating CM through observation and periodic examination. ${ }^{15}$

In the present cases, we have confirmed the presence of calcification within the root canal with the help of CBCT. The confirmation of canal preoperatively prevents inadvertent iatrogenic complication, excess removal of tooth structure, and also saves time. Thus, based on CBCT findings, conservative treatment approach can be followed for treating cases with CM.

Many a times when the routine radiology fails to detect a calcified canal which leads to agitated mind, overzealous cavity preparation is in process of locating the canals. To avoid this complication, CBCT proves to be a valuable tool.

\section{REFERENCES}

1. Arai Y, Tammisalo E, Iwai K, Hashimoto K, Shinoda K. Development of a compact computed tomographic apparatus for dental use. Dentomaxillofac Radiol 1999 Jul;28(4): 245-248.

2. Matherne RP, Angelopoulos C, Kulild JC, Tira D. Use of conebeam computed tomography to identify root canal systems in vitro. J Endod 2008 Jan;34(1):87-89.

3. Nodehi D, Pahlevankashi M, Moghaddam MA, Nategh B. Cone beam computed tomography functionalities in dentistry. Int J Contemp Dent Med Rev. 2015 Jul 18;2015:Article ID: 040515.

4. McCabe PS, Dummer PMH. Pulp canal obliteration: an endodontic diagnosis and treatment challenge. Int Endod J 2012 Feb1;45(2):177-197. 
5. Hillmann G, Geurtsen W. Light-microscopical investigation of the distribution of extracellular matrix molecules and calcifications in human dental pulps of various ages. Cell Tissue Res 1997 Jun1;289:145-154.

6. Langland OE, Langlais RP. Early pioneers of oral and maxillofacial radiology. Oral Surg Oral Med Oral Pathol Oral Radiol Endod 1995 Nov30;80(5):496-511.

7. Jacobsohn PH, Fedran RJ. Making darkness visible: the discovery of X-ray and its introduction to dentistry. J Am Dent Assoc 1995 Oct31;126(10):1359-1367.

8. Farman AG, Levato CM, Scarfe WC. 3D X-ray: an update. Insid Dent 2007 Jun;3(6):70-74.

9. Todd R. Cone beam computed tomography updated technology for endodontic diagnosis. Dent Clin N Am. 2014 Jul 31;58(3):523-543.

10. Patil S, Keshava Prasad BS, Shashikala K. Cone beam computed tomography: adding three dimensions to endodontics. Int Dent Med J Adv Res 2015;1:1-6.

11. Patel S, Dawood A, Ford TP, Whaites E. The potential applications of cone beam computed tomography in the management of endodontic problems. Int Endod J 2007 Oct 1;40(10):818-830.

12. Cotton TP, Geisler TM, Holden DT, Schwartz SA, Schindler WG. Endodontic applications of cone-beam volumetric tomography. J Endod 2007 Sep 30;33(9):1121-1132.

13. Simon JH, Enciso R, Malfaz JM, Roges R, Bailey-Perry M, Patel A. Differential diagnosis of large periapical lesions using cone-beam computed tomography measurements and biopsy. J Endod 2006 Sep30;32:833-837.

14. Gutmann, JL. Problem solving in endodontics: prevention, identification, and management. 3rd ed. St Louis: Mosby, 1997.

15. Amir FA, Gutmann JL, Witherspoon DE. Calcific metamorphosis: a challenge in endodontic diagnosis and treatment. Quintessence Int 2001 Jun1;32(6):447-455.

16. Selden HS. The role of a dental operating microscope in improved nonsurgical treatment of "calcified" canals. Oral Surg Oral Med Oral Pathol 1989 Jul31;68(1):93-98.

17. Şener S, Cobankara FK, Akgünlü F. Calcifications of the pulp chamber: prevalence and implicated factors. Clin Oral Investig 2009 Jun 1;13(2):209-215.

18. De Cleen M. Obliteration of pulp canal space after concussion and subluxation: endodontic considerations. Quintessence Int 2002 Oct 1;33(9):661-669.

19. Garg P, Singh U, Tyagi S, Chaman C. Root canals-from concretion to patency. Saudi Endod J 2015 Jan1;5(1):13.

20. Andreasen FM, Zhjie Y, Thomsen BL, Andersen PK. Occurrence of pulp canal obliteration after luxation injuries in the permanent dentition. Endod Dent Traumatol 1987 Jun 1;3: 103-115.

21. Lundberg M, Cvek M. A light microscopy study of pulps from traumatized permanent incisors with reduced pulpal lumen. Acta Odontol Scand 1980 Jan 1;38:89-94. 